\title{
O PROCESSO DE ESCOLHA DE MINISTROS PARA O SUPREMO TRIBUNAL FEDERAL E POSSIBILIDADES DE DEMOCRATIZAÇÃO DO PODER JUDICIÁRIO
}

\author{
Jose Ribas Vieira ${ }^{1}$ \\ Pedro D'Angelo da Costa ${ }^{2}$ \\ Pedro Henrique Favilla Duarte ${ }^{3}$ \\ Thiago Filippo Silva Jorge ${ }^{4}$
}

\begin{abstract}
Resumo
O Supremo Tribunal Federal é a máxima instância deliberativa do Poder Judiciário brasileiro, cabendo a este órgão todas as discussões que envolvem dispositivos constitucionais. A corte é composta por onze ministros, que enfrentam um procedimento envolvendo indicação do Poder Executivo e aprovação pelo Senado Federal para ocuparem uma cadeira no STF. Neste artigo, pretendemos compreender o cenário político e as movimentações sociais que delineiam esse processo, por meio da análise da pesquisa realizada na Fundação Getúlio Vargas: "História Oral do Supremo Tribunal Federal". A partir das narrativas dos próprios ministros indicados para o Supremo, iremos observar esse processo à luz da capacidade de participação e intervenção da sociedade nas decisões relativas ao tema, o que chamamos de participação popular. Utilizamos o critério da participação devido ao acontecimento recente envolvendo a indicação de um jurista à Corte Suprema de Justiça da Nação Argentina, caso que evidenciou a importância de mecanismos (nesse caso, o Decreto 222/2003) que garantam maior intervenção da sociedade nos processos institucionais. Como embasamento teórico, utilizamos a doutrina de Roberto Gargarella acerca do Constitucionalismo Latino-Americano, e suas observações sobre as teorias constitucionais presentes em nosso continente. Com isso, buscaremos resgatar as características da teoria constitucional republicana como fundamentos jurídicos para a criação e implementação de instrumentos de participação popular.
\end{abstract}

Palavras-chave: Supremo Tribunal Federal; Constitucionalismo; Cortes Constitucionais; Suprema Corte de Justiça da Nação Argentina; Participação Popular.

\footnotetext{
${ }^{1}$ Pós-doutorado em Direito na Université Montpellier I - CERTE, com bolsa CAPES (1985-86). Professor Associado da Pontifícia Universidade Católica do Rio de Janeiro, Professor Titular da Universidade Federal do Rio de Janeiro, Consultor ad hoc da Fundação de Amparo à Pesquisa do Estado de São Paulo e Presidente da Comissão Permanente de Direito Constitucional do Instituto dos Advogados Brasileiro - IAB. Pesquisador-coordenador do Grupo de Pesquisa CNPq Observatório da Justiça Brasileira - OJB-UFRJ. Coordenador do PPGD-UFRJ (2015-2017).E-mail: jribas@puc-rio.br

${ }^{2}$ Mestrando em Direito (área de concentração: Teorias Jurídicas Contemporâneas), no Programa de Pós-Graduação em Direito da Universidade Federal do Rio de Janeiro (PPGD - UFRJ), na linha de pesquisa: Sociedade, Direitos Humanos e Arte, na condição de bolsista CAPES. Participa do Núcleo de Cultura Jurídica, grupo de pesquisa na área da Antropologia Jurídica. E-mail: pedrodangelodacosta@gmail.com

${ }^{3}$ Mestrando em Direito pela Universidade Federal do Rio de Janeiro (UFRJ). E-mail: pedroduarteadv@gmail.com

${ }^{4}$ Mestrando em Teorias Jurídicas Contemporâneas na UFRJ. Bacharel em Direito na FGV Direito Rio. E-mail: thiagofilippo@gmail.com
} 


\section{INTRODUÇÃO}

Autoritarismo, elitismo, dependência econômica e uma imensa desigualdade social foram marcas indeléveis na história das formações sociais latinoamericanas (GARGARELLA, 2010). Tal qual uma cicatriz na pele, ainda se fazem sentir nos dias atuais, especialmente na práxis diuturna das instituições estatais e em sua incapacidade crônica de se democratizarem. A crise política e a instabilidade institucional ocasionada por disputas entre facções do mesmo bloco dominante (MARINI, 2012) tornaram-se a moeda corrente na história constitucional da região. Apesar da importação de alguns modelos teóricos externos, muitos dos quais deslocados de seus eixos epistemológicos e das dinâmicas sociais de suas origens (SCHWARTZ, 2000), a grande contribuição teórica do pensamento contestador da segunda metade do século XX foi o populismo (LACLAU, 2013), entendido como uma reação sincera e oportuna ao legado histórico herdado.

Contudo, a redemocratização vivida nos últimos trinta anos na América Latina e o novo movimento constituinte por que passou a região (ELSTER, 1995), após violentas ditaduras militares, as quais exacerbaram todo o tipo de violência e iniquidades (BARROS, 2004), um novo paradigma constitucional surgiu (NINO, 1996). Ainda que o pensamento radical conflitivo tenha uma certa influência e um peso decisivo na teoria constitucional da região (MÉDICI, 2010), apontando para a conformação de uma tendência contemporânea no Constitucionalismo Latino-Americano, fato é que a aposta teórica do momento é a busca de um modelo de democracia deliberativa. Isto é, a redistribuição dos poderes políticos e a abertura democrática das instituições serviriam como mudança radical para efetivar direitos econômicos e sociais e, consequentemente, livrar a região dos estigmas associados ao atraso estrutural. Entendemos que parte dessas iniciativas são fruto do resgate das teorias constitucionais republicanas, na definição de Roberto Gargarella, (GARGARELLA, 2013), que tiveram início com a formação dos Estados latino-americanos e permeiam a história constitucional de nosso continente. Os pressupostos dessas teorias determinam como central a democracia direta e a legitimidade de um governo apoiado pela maioria da população, em contraposição a outras posturas teóricas ligadas ao individualismo e ao elitismo político. Como se pode notar, é uma aposta alta e ousada, como foram as apostas teóricas anteriores, capaz de conquistar corações e mentes de reformadores sociais latino-americanos para um modelo idílico de democracia e direitos fundamentais.

Em paralelo a toda essa efervescência teórica, continua existindo uma compreensão elitista sobre as instituições e sobre o papel da democracia na conformação das formações sociais. Elites políticas e econômicas ainda excluem a imensa maioria dos cidadãos de decisões políticas elementares, sob o rótulo de decisões técnicas (BINENBOJM, 2015), ou de uma concepção extremamente autoritária na tomada de decisões (ARAGÃO, 2002). Mesmo sendo natural a fricção entre o ideal de reformadores e a prática das instituições políticas, no contexto latino-americano o desrespeito à cidadania e as regras do jogo democrático potencializam os atritos 
sociais existentes.

Diante do exposto, este artigo se debruçará sobre o processo de escolha de ministros para o Supremo Tribunal Federal brasileiro. A escolha do objeto de análise levou em consideração as tensões existentes entre a democracia representativa e a contramajoritariedade da jurisdição constitucional. O déficit democrático do exercício desse mister pela Corte Suprema necessita de algum lastro democrático justificante. Uma possibilidade seria a participação popular no procedimento de escolha dos candidatos à vaga de ministro. Todavia, como o presente artigo pretende demonstrar, isso não só não ocorre, como também, no caso brasileiro, a aproximação política das indicações do Executivo e a chancela sempre deferente do Senado promovem uma baixa participação dos segmentos organizados da sociedade civil.

Dessarte será apresentado o quadro do processo de indicação constitucional para a Suprema Corte argentina. Lá a prevalência do Decreto 222/2003 permitiu um significativo avanço democrático no processo vestibular dos juízes constitucionais. Por sua vez, a crise institucional provocada pela indicação do jovem jurista Roberto Manuel Carlés foi o estopim de reações da sociedade civil portenha que, de uma forma ou de outra conseguiu influir significativamente na escolha. O Decreto 222/2003 nos ajuda a exemplificar o embasamento teórico trazido anteriormente, já que funciona como uma ferramenta de efetiva participação popular, como procuraremos demonstrar. Essa comparação entre as experiências recentes do Brasil e da Argentina serviriam para demonstrar o atraso a qual nos encontramos nas discussões e implementações de reformas democráticas.

Por isso, o presente artigo se estrutura da seguinte forma: $O$ primeiro capítulo é dedicado ao processo brasileiro atual. O enfoque se dá pela história oral do Supremo Tribunal Federal da Nova República e as indicações e o processo de seleção de novos ministros para compor a Corte Constitucional. A segunda parte dedica-se ao estudo do caso argentino e o processo de renúncia do então ministro Eugênio Raul Zaffaroni e a nomeação e reação da sociedade civil na indicação de Roberto Manuel Carlés e, como isso foi potencializado pelo supracitado decreto 222/2003. Após, aprofundaremos a análise teórica a partida da observação das características, atribuídas por Gargarella, da teoria constitucional republicana, fruto do pensamento social latino-americano, por entendermos que os regastes conceituais e as releituras dessa teoria constitucional são responsáveis pelo atual acúmulo social e político capaz de direcionar as formulações práticas na direção de um processo democratizador. Por fim, serão apresentadas as conclusões sobre as potencialidades democráticas do processo brasileiro e o estudo comparativo poderá revelar o grau de atraso e instabilidade provocado pela concepção elitista e autoritária dos processos de indicação brasileiros.

\section{O PROCESSO DE ESCOLHA DE JUIZES DA SUPREMA CORTE DO BRASIL: HISTORICIDADE E RELATOS}


Outrora tendo sido o ápice do Judiciário brasileiro o Supremo Tribunal de Justiça do Império, a partir do Decreto n. ${ }^{\circ} 848$ de 1890 (TAVARES FILHO, 2006, p.4), o Supremo Tribunal Federal passou a figurar nesta posição que mantêm até hoje. Além do nome, também a forma de seleção dos juízes (que, pela tradição nacional, são chamados de Ministros) que a formam permaneceu praticamente estável neste intervalo de tempo.

A dinâmica de introdução de novos Ministros à Corte a partir de uma indicação do Presidente da República que então pode ser confirmada ou rejeitada pelo Senado Federal pouco mudou desde a sua origem. Comparem as redações:

Da Constituição de 1890:

Art. 56 - O Supremo Tribunal Federal compor-se-á de quinze Juízes, nomeados na forma do art. $48, n^{\circ} 12$, dentre os cidadãos de notável saber e reputação, elegíveis para o Senado.

E na Constituição de 1988:

Art. 101. O Supremo Tribunal Federal compõe-se de onze Ministros, escolhidos dentre cidadãos com mais de trinta e cinco e menos de sessenta e cinco anos de idade, de notável saber jurídico e reputação ilibada.

Necessário apontar que há duas especificidades que diferenciam o atual regime constitucional, como o acréscimo do qualificador "jurídico" ao requisito de "notável saber"; também estão agora os Ministros do Supremo Tribunal Federal sujeitos à aposentadoria compulsória aos 75 anos (art. 40, \$1º, II, CFRB/1988), não sendo mais o cargo vitalício; os Ministros do STF somente podem ser brasileiros natos (art. 12, $\$ 3^{\circ}$, IV, CFRB/1988) e a aprovação do Senado dá-se por maioria absoluta (art. 101, parágrafo único, CFRB/1988).

À luz da teoria de Gargarella, o modelo republicano na América Latina dá um lugar especial ao ideal de autogoverno. Analisado sob esta luz, as categorias abertas "notável saber jurídico" e "reputação ilibada" podem ser compreendidas como um critério democrático, ou seja, haveria um espaço de debate público para que se considere alguém qualificado para ocupar o cargo de Ministro do Supremo Tribunal Federal de acordo com o preenchimento destas condições, que, por sua vagueza, estão abertas a interpretação. Se assim o fosse, este meio de indicação, apesar de indireto - isto é, feito e ratificado por representantes políticos - estabeleceria uma comunicação com o mundo exterior.

Um aspecto interessante do "notável saber jurídico" é que, formalmente, não se requer o grau de bacharel em Direito para que um candidato se qualifique para o cargo; toda a regulação sobre esta categoria está no artigo constitucional que a estabelece e foi acima transcrito. No entanto, após um caso em particular da nossa história, não ocorreram mais indicações para o STF de pessoas que não tivessem este diploma. Trata-se do episódio em que Floriano Peixoto indicou o médico Barata Ribeiro em 1893, cargo que ocupou por um breve período, até que, em 1894, a Comissão de Justiça e Legislação do Senado Federal deu parecer contrário à aprovação desta indicação, entendendo que o Dr.

Barata Ribeiro, por ser médico, não atendia ao requisito de "notável saber jurídico" (OLIVEIRA, 2009). Posteriormente, Floriano Peixoto indicou dois generais ao Supremo Tribunal Federal, situações nas quais foi vol.10, nº. 01, Rio de Janeiro, 2017.pp. 1-23 
mobilizado o mesmo parecer para rejeitar as indicações (OLIVEIRA, 2009).

No intervalo entre as Constituições de 1891, poucas alterações no regime de indicações podem ser relatadas. A mais substancial delas está na delegação da aprovação do indicado ao Conselho Federal na Constituição de 1937, quando o Estado Novo de Getúlio Vargas extinguiu o Senado. Além disto, diversas alterações no número total de juízes foram operadas, o que pode constituir-se em oportunidades de indicação, mas ainda assim não são a matéria deste artigo ${ }^{5}$.

Um aspecto interessante é que a história do Supremo Tribunal Federal é marcada por pouquíssimas rejeições por parte do Senado Federal. Na verdade, em nenhum outro período além de o da presidência de Floriano Peixoto foram rejeitadas indicações de Ministros do Supremo Tribunal Federal. Enquanto Floriano Peixoto enfrentou cinco rejeições (MELLO, 2012, p. 18), os demais Presidentes tiveram suas escolhas mantidas com facilidade. Se avaliados apenas os resultados, pode-se ter a impressão que os Presidentes da República enfrentam pouca ou nenhuma resistência às suas indicações. Os relatos de indicações recentes, no entanto, problematizam esta conclusão.

Antes de se iniciar a análise destes relatos, uma observação sobre estas rejeições. A análise de Oliveira (2009) conclui que não só as indicações que evidentemente não preenchiam os requisitos, como a de um médico a um cargo que exige "notável saber jurídico" tiveram insucesso, mas que quase todas as indicações de Floriano enfrentaram um elevado grau de atrito, sendo as aprovações feitas com poucos votos mais a favor que contra. A autora diz que a análise do material jornalístico da época permite relacionar a dinâmica destas votações ao contexto político do período em questão.

Os relatos são dados coletados pelas equipes do CPDOC, Direito Rio e GV Direito no projeto de "História Oral do Supremo Tribunal Federal", da FGV ("HOSTF" daqui em diante) ${ }^{6}$. A expressão "história oral" designa, conforme o prefácio das obras em questão, um “método-fonte-técnica”. Trata-se de um método pois é uma abordagem historiográfica que busca um dado histórico específico, as narrativas sobre a história, em detrimento de fatos históricos. Para tanto, procura-se obter relatos de personalidades associadas ao fenômeno histórico em questão, constituindo a história oral uma fonte de dados históricos qualitativamente diferente daqueles produzidos em outras abordagens historiográficas, como as pesquisas documentais. Por fim, o termo designa uma técnica específica de condução de entrevistas, em que o entrevistado é levado a produzir um relato autobiográfico em ordem cronológica, iniciando-se com o nascimento do entrevistado até o momento em que a

\footnotetext{
${ }^{5}$ Interessados neste e em outros dados históricos, consultar MELLO, José Celso de. Notas sobre o Supremo Tribunal (Império e República). Brasília: Supremo Tribunal Federal. 3ª ed. 2012. Disponível online em:

http://www.stf.jus.br/arquivo/cms/publicacaoPublicacaoInstitucionalCuriosidade/anexo/Notas_informativ as_sobre_o_STF_versao_de_2012.pdf, último acesso em 04/11/2015.

${ }_{6}$ As entrevistas realizadas estão sendo publicadas pouco a pouco e disponibilizadas gratuitamente no site do projeto, https://bibliotecadigital.fgv.br/dspace/handle/10438/13570. Até o momento do último acesso, em 04/11/2015, haviam sido publicados os dez primeiros volumes.
} 
entrevista é dada.

Uma última observação é de que, embora neste artigo tratemos de toda a história de indicações de Ministros ao STF, a pesquisa produzida pela FGV tem um recorte temporal menor: Apenas contempla aqueles que atuaram como Ministros no atual contexto constitucional, isto é, depois de outubro de 1988.

A primeira narrativa das entrevistas disponíveis é a de Sepúlveda Pertence. Este Ministro tinha como pano de fundo ter sido assistente no Supremo Tribunal Federal e ser, à época, Procurador-Geral da República. Quando perguntado sobre ter tido vontade de ser Ministro do STF, respondeu negativamente. Apesar de consciente de outros procuradores-gerais terem feito a transição para Ministro, Pertence declara nunca ter colocado a possibilidade de ser Ministro como uma aspiração pessoal ou política (HOSTF vol. 3, p. 85). Segundo ele:

Isso envolveria algo extremamente desagradável, que era a procura de apoio possível e pressões e manifestos dirigidos ao presidente da República, como depois eu pude verificar no arquivo da correspondência do presidente Sarney, que está lá no convento de São Luís. (...). Eu verifiquei algumas campanhas para o Supremo Tribunal. (HOSTF, p. 86)

Dessa forma, Pertence declarou não ter feito campanha para o STF, assim como recusou a oferta de aliados para que o fizessem. Porém, com a implantação da Constituição de 1988, passou-se a se exigir, para o cargo que Pertence então ocupava, o de Procurador-Geral da República, que fosse este um membro da carreira. Em audiência com o Presidente Sarney, este revelou a Pertence haver pressão do Ministério Público para que fosse aplicada a Constituição e que o cargo fosse ocupado por alguém que preenchesse este novo requisito. $\mathrm{Na}$ entrevista, Pertence declarou que respondeu mostrando-se disposto a voltar ao seu escritório de advocacia. Sarney, no entanto, teria respondido que só o destituiria do cargo quando houvesse vaga no Supremo Tribunal Federal, o que ocorreu com a indicação de Oscar Dias Corrêa ao Ministério da Justiça.

O relato sobre a sabatina é maior e merece mais atenção, principalmente por ser, dentro do âmbito de dados colhidos neste artigo, o mais detalhado. Sepúlveda Pertence lembra que, à época, somente poderia representar a inconstitucionalidade de uma lei o Procurador-Geral da República, o cargo que ele ocupava antes de ir ao STF. Assim, chegou às suas mãos uma lista de um grande número de senadores e deputados, encabeçada pelo senador Roberto Campos, pedindo-lhe que representasse a inconstitucionalidade da Lei de Informática, uma mobilização entendida como internacional, principalmente pelos interesses estadunidenses em jogo. Afirmou que a lista tinha a maioria do Senado e um grande número de deputados. Partindo de um entendimento que era considerado quase uma ofensa pessoal (HOSTF, p. 88) negar-se a assinar a lista, Pertence optou por encaminhar a representação ao Supremo Tribunal Federal, mas, ao contrário da prática comum, apresentou junto à representação seu parecer pessoal a favor da constitucionalidade da lei. No contexto desta polêmica, Pertence surpreende-se que o relator do seu processo de nomeação na Comissão de Justiça era Roberto Campos que não vol.10, nº. 01, Rio de Janeiro, 2017.pp. 1-23 
era membro da Comissão (HOSTF, p. 89). Segundo o relato, Roberto Campos foi um dos primeiros a questionálo também quando a questão foi ao plenário, e começou da seguinte forma sua questão:

Senhor presidente, para ser Ministro do Supremo, pressupõe-se saber jurídico, gosto pelo trabalho e ilibada reputação, ou moralidade induvidosa. A esse senhor que hoje está aqui como candidato a Ministro do Supremo, eu tenho o desprazer de dizer que lhe faltam todas essas qualidades (HOSTF, p. 89).

Após este começo, Roberto Campos teria seguido falando sobre a demora na representação da inconstitucionalidade da Lei de Informática. Sepúlveda Pertence, então, descreve ter respondido: $O$ senador Roberto Campos deve desconhecer, mas a nossa animosidade vem de muito antes (HOSTF, p. 90) e seguiu na resposta falando da mobilização política da UNE, encabeçada por Pertence, na qual Roberto Campos era o símbolo do entreguismo, na linguagem política da época (HOSTF, p. 90). Apesar de ter tido que combater a animosidade do relator e o nervosismo por isto provocado, a aprovação na sabatina é qualificada como tranquila, contra o voto quase solitário do senador Roberto Campos (HOSTF, p. 90). Sobre as demais perguntas, declarou terem sido sobre questóes jurídicas, questóes de estrutura do Judiciário (HOSTF, p. 90). Quando perguntado se houve questões que tentassem adiantar sua atuação no STF, respondeu que, quando questionado sobre matérias que estavam ou ameaçavam estar nas próximas pautas do STF (HOSTF, p. 91), evitou a questão respondendo que pediria vista. Pertence encerra seu relato pontuando que recebeu apoio de aliados políticos na sabatina, assim como o relator no plenário, que havia sido seu colega da faculdade, Maurício Corrêa.

Aqui, percebe-se que o atrito político nada tem a ver com participação popular ou com interesses públicos mais amplos. O movimento de saída de Pertence de seu cargo anterior se deu em razão dos interesses de um setor profissional restrito, e, pode-se argumentar, de elite. A narrativa sobre a entrada pode ser analisada tanto sobre atores quanto sobre interesses. Em questão de atores, restringiu-se a um debate sobre o jogo político de representantes. Em questão de interesses, pode-se entender que havia interesses mais amplos em jogo - a forma de regularidade constitucional a partir da representação de inconstitucionalidade, os interesses de relações internacionais contidos no debate da Lei de Informática, e, por fim, a forma de se relacionar com o passado dos governos militares contidas nas memórias da UNE. Ainda assim, não há evidência de qualquer envolvimento popular direto.

Em contraste, a experiência de Carlos Velloso é descrita brevemente. Sobre ela, disse o Ministro: Foi boa. (HOSTF vol. 7, p. 166). Disse também ser útil(HOSTF vol. 7, p. 166), pois teve a oportunidade de discorrer suas posições sobre o Judiciário. O então Senador Maurício Corrêa, que de acordo com Velloso tinha sido seu colega de faculdade em Belo Horizonte, trouxe à tona a temática dos advogados e sua relação com os juízes. Velloso encerra seu relato dizendo que passou a maior parte da sabatina discorrendo sobre o Poder Judiciário e sobre a Constituição que fora promulgada menos de dois anos antes (HOSTF, p. 168), e deixei expresso, invocando o Pertence, que não há Constituição outra que tenha conferido ao Poder Judiciário tamanho valor, que tenha 
confiado tanto nos juízes quanto a Constituição democrática de 1988. (HOSTF vol. 7, p. 166)

Já Nelson Jobim, quando perguntado sobre a sabatina, a primeira reação foi acerca do tempo: Levou quatro, cinco, cinco horas, seis horas de sabatina. (...). Foi enorme (HOSTF vol. 9, p. 190). Quando provocado a explicar porque foi tão longa, Jobim declara: Porque a verdade é o seguinte: você sabe que, nessas sabatinas, parte de perguntas já são preestabelecidas e outras se dão na base do elogio (HOSTF, pp. 190191). Declarou ter uma cópia da sabatina em VHS e que dois temas tomaram muito tempo: A questão das terras indígenas como o caso Raposa Serra do Sol e a atuação de Jobim na revisão constitucional. Sobre esta última, disse Jobim haver uma série de críticas partindo da esquerda radical (HOSTF, p. 191) às posições que ele sustentou durante a reforma. Em resposta, Jobim relembrou das disputas dentro do partido comunista da China com as reformas empreendidas por Deng Xiaoping, as comparando com as disputas da esquerda brasileira. Nas palavras dele:

E eu fazia esses jogos de... Enfim, das... digamos, das contradições internas e as disputas da esquerda. E eu, além do mais, conhecia também as disputas internas da esquerda brasileira, partido, PRC, aquelas coisas todas. Mas a entrevista foi longa. Foi longa, mas saiu tudo bem. (HOSTF, p. 192).

Também detalhou Jobim que outro grande trecho foi dedicado às questões sobre o papel do STF e do judiciário. Narrou sustentar a necessidade de modernização do judiciário, visto que o sistema judiciário brasileiro estava defasado em relação à modernidade dos conflitos (HOSTF, p. 192). Um de seus exemplos foi ter exposto a percepção de estar o judiciário voltado a conflitos individuais, mas despreparado para lidar com conflitos individuais que contivessem interesses coletivos. Outro aspecto que Jobim parece ter enfatizado - não é claro na entrevista, dado que logo depois o Ministro emendou outro assunto - era o despreparo dos juízes em relação aos casos que envolvem a economia, uma vez que estes estão preparados mentalmente para servir justiça às partes de um processo, mas não à massa com demandas similares.

O relato de Jobim leva a considerações mais sérias sobre a representatividade do debate público nas sabatinas. Ainda que este relate um espaço dedicado ao modelo de judiciário, Jobim deixa claro que, em suas memórias, preponderou em sua o jogo político em dois aspectos: A postura deferente dos Senadores (a partir de perguntas preestabelecidas e os elogios) e lidar com a oposição, o que é feito com a própria exposição do jogo político e as contradições internas. Assim sendo, pouco se dá voz às preocupações públicas do país, enfatizando-se o círculo formado por aqueles que centralizam o poder político.

Já o Ministro Cezar Peluso fez outro relato complexo. O Ministro narra, primeiramente, um movimento de vários advogados de São Paulo, entre eles, Márcio Thomaz Bastos, de apoiarem a ida de Peluso ao Superior Tribunal de Justiça. No entanto, Thomaz Bastos perguntou à Peluso se este não preferia o STF. Tendo resposta positiva, ele começou a articular um trabalho na área dele, com os conhecidos dele e etc. (HOSTF vol. 4, p. 125). No entanto, Lula já havia indicado um candidato (HOSTF vol. 4, p. 125).

Dá-se ênfase pois a expressão "candidato", acredita-se, é significativa de uma perspectiva diferenciada vol.10, nº. 01, Rio de Janeiro, 2017.pp. 1-23 
sobre o processo de indicação. Tratava-se de Ellen Gracie. Depois desta, houve a indicação de Gilmar Mendes. Mas ficou o trabalho (HOSTF vol. 4, p. 125). Para Peluso, isto foi importante para sua eventual indicação pois esta movimentação representava a opinião dos advogados de São Paulo (HOSTF, p. 126), assim como a de juízes e demais juristas. Além de Thomaz Bastos, dois presidentes do Tribunal de Justiça de São Paulo teriam apoiado Peluso, assim como um cardeal, teriam apoiado esta candidatura. Peluso especula também que o já Ministro Celso de Mello também tenha o apoiado, por terem sido conhecidos na época em que Celso de Mello foi promotor. Quando Márcio Thomaz Bastos tornou-se Ministro da Justiça, Peluso narra uma movimentação interministerial para apoiá-lo. José Paulo Pertence teria dito: Olha, o Supremo Tribunal Federal está esperando o Peluso, a nomeação dele (HOSTF, p. 128). Por fim, Peluso descreve ter havido movimentação de políticos e do PSDB a seu favor.

Acerca da sabatina, Peluso a caracteriza como tranquila (HOSFT, p. 130), creditando isto a uma longa exposição introdutória que fez, em respeito aos debates empreendidos ao longo do esforço de nomeação, em que o Ministro buscou esclarecer as verdades e mentiras sobre os seus posicionamentos. Depois começaram as perguntas. Nenhuma delas deselegante. Também nenhuma impossível de responder. Eu fui respondendo todas (HOSTF, p. 131). Também se recorda de ter tido senadores que não remanesceram por toda a sabatina, que segundo ele foi uma sabatina longa, quatro horas (HOSTF, p. 131), manifestando votos a favor dele antes de sair. Além disto, os três votos contrários, segundo a entrevista, não o afetaram, sendo de praxe (...) de ter sempre dois, três votos contra (HOSTF, p. 131).

Reforça-se, por este relato, que a mobilização por uma indicação ao STF não pode ser caracterizada como "pública". Trata-se de um esforço empreendido por setores extremamente parciais da sociedade, e, pode-se entender, elitários. A forma de relatar do Ministro - sendo capaz de apontar uma figura representativa para cada um de seus setores de apoio - é evidência ainda maior da individualização, em vez de publicização, do apoio às indicações destes juízes.

Por fim, temos as declarações de Eros Grau. O contato inicial relatado partiu de Márcio Thomaz Bastos, que notificou Grau de que ele seria convidado para ser Ministros do STF e indicado pelo Presidente. Grau, que havia sido chamado a Brasília (HOSTF vol. 10, p. 63) foi orientado a remanescer em São Paulo. Grau também conta que, antes de encontrar-se com o Presidente, foi convidado para conversar com um membro do

Poder Judiciário. Sobre esta reunião, realizada no gabinete desta pessoa, Eros Grau conta: Quando deu uma hora de conversa, essa pessoa disse que queria me fazer uma confidência, que essa pessoa era candidata ao Supremo e se eu poderia falar com o ministro da Justiça a respeito disso. (HOSTF, p. 63).

Em seguida, Eros diz ter telefonado a Thomaz Bastos para narrar a conversa, mas que a "candidata" (HOSTF, p. 64) não tomou seu lugar. Em vez disto, um tempo depois foi chamado para conversar com o Presidente em Brasília. Sobre o encontro com o Presidente, Grau recorda que já o conhecia de São Paulo e do vol.10, no. 01, Rio de Janeiro, 2017.pp. 1-23 
Conselho de Desenvolvimento Econômico e que tiveram uma breve conversa descontraída, de três a quatro minutos.

Após isto, Eros Grau disse ter sido orientado por alguém, que não se recordava ser Márcio Thomaz Bastos ou Nelson Jobim, que havia a prática de se visitar o Senado. De acordo com Eros Grau, visitou Sarney, Agripino Maia, Edison Lobão, este último, segundo lembrou, era da Comissão de Constituição e Justiça. Sobre estas visitas, disse Eros tratar-se de visitas de cortesia, para saber quando seria marcada a sabatina. Também relatou ter conversado com Sarney sobre literatura, sobre um autor pouco conhecido que ambos conheciam. Depois deste dia, teria retornado ao Senado somente no dia da sabatina.

Acerca da sabatina em si, a primeira recordação narrada foi uma das grandes surpresas e decepçóes da minha vida: decepção porque ele era o tipo do sujeito que eu não deveria gostar dele, e eu fiquei encantado com a gentileza dele e surpreso com a delicadeza e gentileza desse sujeito (HOSTF, p. 65). Tratava-se de Antonio Carlos Magalhães. Narra Eros Grau que este foi gentil e levou em consideração o momento de tensão pelo qual ele passava, na condição de sabatina. Sobre a sabatina em si, diz não ter havido nenhuma pergunta delicada (HOSTF, p. 65). Explicou desta forma as razões porque sua sabatina foi tranquila e porque outras podem não ter sido similarmente tranquilas:

Não havia tensão naquele momento. As relações entre Senado, Executivo e Judiciário eram muito mais adequadas ao princípio republicano do que as de hoje. Quer dizer, hoje. Porque a violência não é apenas violência no sentido de torturar fisicamente, mas é, também, violência no sentido de atropelar as instituições. (...). Isso é uma violência que talvez não tenha a mesma repercussão da violência física porque a Constituição e os regimentos não sentem dor, mas é quase o mesmo tipo de violência. (HOSTF, p. 66).

Por fim, Eros Grau relatou ter recebido apoio de setores como os seus contatos na USP, mas que estes apoiadores de sua nomeação mais tarde se decepcionaram com sua atuação no Supremo, porque esperavam que ele atuasse para empreender políticas de esquerda e, em vez disto, ele foi um juiz positivista (HOSTF p. 67).

Apesar destes relatos conterem muitas particularidades, pode ser traçado um panorama acerca das sabatinas. Os relatos põem em evidência a mobilização para a indicação não por parte de setores amplos da sociedade, mas sim uma restrita parcela, entre juristas e a classe política. Mesmo Jobim, que, à época de sua nomeação, tinha deixado o cargo de deputado federal para ser Ministro da Justiça, não citou mobilização de seu eleitorado. Assim como Peluso, cuja indicação foi viabilizada por apoio de São Paulo, detalhou que este partia de advogados e juízes paulistas, assim como a de um membro de uma outra elite, a religiosa, na figura de um cardeal. Um outro aspecto é que é que a qualificação para o cargo prepondera nos relatos em que não foram descritas enormes resistências à indicação; por outro lado, a capacidade de lidar com as críticas e rebatê-las foi enfatizada nos demais. Assim, na memória coletiva dos Ministros, o aspecto político foi central no processo de indicação e a consequente nomeação, acima dos requisitos jurídicos para a pertença ao STF, ainda que estes sejam abstratos. Não observamos nenhuma participação ou possibilidade de intervenção mais ampla da sociedade no decorrer do vol.10, no. 01, Rio de Janeiro, 2017.pp. 1-23 
processo de escolha de um novo ministro. Por fim, o teor dos conflitos políticos narrados pode ser interpretado como evidência de que o aspecto chave na resistência a um determinado candidato são as tensões entre as instituições, em particular entre o Executivo e o Legislativo.

\section{PARTICIPAÇÃO POPULAR NA CORTE SUPREMA DE JUSTIÇA DA NAÇÃO ARGENTINA}

No capítulo anterior, analisamos detidamente, através dos relatos apresentados, como se dá o processo de indicação e nomeação de ministros para o Supremo Tribunal Federal, no Brasil. Agora, nos dedicaremos a observar esse mesmo processo em instituição semelhante, A Corte Suprema de Justiça da Nação Argentina. Faremos esse paralelo com o objetivo principal de analisar o Decreto 222/2003, do então presidente Néstor Kirchner, que introduziu novos procedimentos ao processo de escolha de ministros para a Corte Suprema.

Como vimos anteriormente, no caso brasileiro, existe pouca ou nenhuma participação popular neste processo, que ocorre exclusivamente através de articulações políticas envolvendo alguns setores da sociedade e os Poderes Executivo, Legislativo e Judiciário. Entretanto, ao observarmos os acontecimentos relacionados à indicação do substituto de Raul Zaffaroni na Corte Suprema da Nação Argentina, concluímos que outros atores participam desse processo, em parte devido às alterações propostas pelo Decreto 222/2003. Aprofundaremos também a análise teórica a luz de Roberto Gargarella acerca desse instrumento de participação popular e o constitucionalismo na América Latina.

\section{Regulamentação constitucional}

A Corte Suprema argentina cumpre papel semelhante ao desempenhando pelo Supremo Tribunal Federal no Brasil, sendo a instância máxima julgadora e competente para discutir dispositivos constitucionais. Segundo o artigo 108 da Constituição argentina, o sistema judiciário é composto pela Corte Suprema de Justiça e demais tribunais inferiores:

Articulo $108^{\circ}$ - El Poder Judicial de la Nación sera ejercido por una Corte Suprema de Justicia, y por los demas tribunales inferiores que el Congreso estableciere en el territorio de la Nacion (ARGENTINA, 1853)

Esse preceito é complementado pelo artigo 111, que determina experiência prévia de oito anos como advogado para o candidato à Corte Suprema. Nesse ponto, existe uma diferença em relação à Constituição brasileira, que não exige a formação em advocacia para o exercício de atividades no Supremo Tribunal Federal, como vimos anteriormente.

O artigo 99 da Constituição argentina traz outro dispositivo referente ao tema, apresentando apenas 
uma pequena diferença quando comparado à nossa Constituição. Segundo o referido artigo, após a indicação pelo chefe do Poder Executivo, o candidato à Corte Suprema deve ter seu nome aprovado pelo Senado Federal com votação de pelo menos dois terços dos senadores. $\mathrm{Na}$ Constituição brasileira, exige-se a aprovação apenas por maioria absoluta.

Com base nesta comparação, concluímos que a norma constitucional que versa sobre a forma de indicação e nomeação de ministros para a Corte Suprema de Justiça em muito se assemelha com a Constituição Federal brasileira, baseando-se no sistema de "freios e contrapesos". Este paradigma remonta à tripartição dos poderes e à teoria presente na obra de iluministas como Montesquieu ${ }^{7}$, já que a decisão do Poder Executivo depende de deliberação do Poder Legislativo. Esta ferramenta parece ter sido adotada pelas teorias constitucionalistas latino-americanas, objetivando a democratização das cortes supremas constitucionais. Porém, o acúmulo político latino-americano em especial resultante das teorias republicanas, com base nas obras de Roberto Gargarella, levou os países na América Latina a desenvolverem outros mecanismos capazes de dialogar com as demandas sociais por mais justiça, transparência e democracia. Sendo assim, o então presidente Néstor Kichner, entendendo a necessidade de maior conhecimento acerca dos critérios de escolha de novos ministros para a Corte Suprema e considerando a necessidade de maior participação popular, editou o Decreto 222/2003, que altera o mecanismo de escolha de um novo ministro.

Temos como base teórica para nossas afirmações a teoria constitucional de Roberto Gargarella, que expõe em suas obras uma reconstrução histórica do Constitucionalismo Latino-Americano e as circunstâncias que levaram os países da América Latina a desenvolverem suas constituições de uma ou outra forma. Para o autor, dois questionamentos guiaram as formulações constitucionais em nosso continente desde sua independência: primero, una pregunta relacionada con el lugar constitucional del ideal de la autonomia individual, y segundo, uma pregunta referida al lugar que reservaran para el ideal del autogobierno colectibo (GARGARELLA, p. 5). Para o autor, a partir das respostas a esses questionamentos, na história do constitucionalismo latino-americano surgem três modelos constitucionais: conservador, republicano e liberal. Não nos cabe aqui uma abordagem mais profunda sobre o constitucionalismo latino-americano, já realizado nas obras de Gargarella; pretendemos aqui analisar questões relativas ao objeto estudado e alguns fundamentos do modelo constitucional republicano.

Segundo Gargarella, a posição republicana:

se distinguió por su enfrentamiento directo com la posición anterior (conservador), a partir de su compromisso fundamental com el ideal del autogobierno; y que tendió a considerar a la autonomia individual como un ideal desplazable en nombre del bienestar general, o las

\footnotetext{
${ }^{7}$ A tripartição dos poderes e a teoria dos "freios e contrapesos", presentes na obra Obras como O espírito das Leis (1748) de Montesquieu, surgem no contexto das revoluções europeias iniciadas no século XVIII, que tinham como um de seus objetivos questionar a forma de governo baseada no Estado absolutista e aristocrático. Entendemos que o embasamento teórico produzido por autores desse período influenciou de modo determinante no pensamento constitucional em diversas localidades por todo o mundo, inclusive na América Latina.
} 


\section{exigências propias de uma política mayoritaria (GARGARELLA, p: 7).}

O modelo republicano (ou radical) surge no contexto das lutas independentistas, como oposição direta ao modelo conservador e demonstrando um anseio de autodeterminação dos povos latino-americano e organização coletiva em torno de um Estado garantidor. Para Gargarella, o modelo republicano se define pelo mayoritarismo politico y, lo que denominaré, a falta de un término mejor, el populismo moral (GARGARELLA, p. 12).

A autoridade das maiorias populares é fator central deste modelo constitucional, que lutava diretamente contra o elitismo político e o autoritarismo praticado pelos conservadores. Disso depreendemos o conceito de populismo moral, que pretendia contrapor-se ao conceito de perfeccionismo moral, postura que pretendia impor determinada religião ou grupo de costumes a toda a sociedade. Roberto Gargarella cita Francisco Bilbao, político chileno, que formula acerca do modelo republicano: Bilbao defiende a la democracia directa frente a quienes consideran que ella es impracticable

(Bilbao 2007, 321-22); define a la delegación del poder legislativo como 'crimen de lesa humanidad' (ibid., 326), como esclavitud disfrazada de soberania (GARGARELLA, p. 13). Como pode ser visto, a democratização do Estado e inclusão de toda a população é pauta central dos republicanos, garantindo a transparência e a democracia como importantes ferramentas de disputa social: Fueron ellos, los radicales, los que más y mejor abogaron por romper un esquema de toma de decisiones excluyente, autoritario, concentrado en unas pocas manos (GARGARELLA, p. 13). Dessa forma, compreendemos que as formas de participação popular na política e democratização das tomadas de decisão advêm de uma teoria constitucional que busca a emancipação do povo, indo de encontro à dominação praticada antes pelas colônias e depois pelas elites. Nossa tese é de que $\mathrm{O}$ decreto 222/2003 representa uma forma de expressão desses postulados, visto que proporciona uma ferramenta de intervenção direta nas decisões de governo e permite maior fiscalização por parte da população.

\section{Impactos do Decreto 222/2003}

O Decreto 222/2003 foi editado em 19 de junho de 2003, nos marcos principiológico da democracia e da participação popular. Neste subitem, estudaremos as disposições deste decreto na tentativa de assimilar suas motivações teóricas e seus impactos concretos na democracia argentina. Suas disposições determinam uma série de mecanismos políticos a serem aplicados com o objetivo de contribuir para a escolha do ministro a ser indicado à cadeira vacante na Corte Suprema argentina. O decreto se refere à dois momentos: a formulação de uma lista pelo Poder Executivo a ser enviada ao Senado da Nação Argentina e também ao momento de discussão dos nomes recebidos pelo Senado na Comissão de Acordos do Senado.

De início, o decreto citado, em suas fundamentações, reivindica como princípios o intuito de escolha do vol.10, n. 01, Rio de Janeiro, 2017.pp. 1-23 
melhor candidato, o melhoramento do serviço de justiça, o fortalecimento do sistema republicano e da qualidade institucional. Dessa forma, percebemos que a explicitação desses princípios direciona a atuação política no sentido de aprimorar os mecanismos democráticos em questão. Logo abaixo desta consideração, ainda na fase de fundamentação, o Decreto 222/2003 vai além de argumentos organizativos do Estado e vincula a escolha de um novo ministro ao respeito às diversidades de gênero e defesa de direitos humanos. Compreendemos que a defesa pública destas perspectivas é um avanço na política latino-americana ainda não observado no ordenamento jurídico brasileiro. O estabelecimento de pautas consideradas progressistas e ligadas a teorias constitucionais republicanas reforçam esta tendência em nosso continente e possibilitam o aprofundamento desta postura do Estado, que busca cada vez mais o equilíbrio social e o aprimoramento da democracia:

Que resulta necesario tener presente, a la hora del ejercicio de tal facultad, las circunstancias atinentes a la composición general del Alto Cuerpo en quanto a diversidades de género, especialidades profesionales e integración con un sentido regional y federal

Que a ello deben sumarse los requisitos relativos a la integridade moral e idoneidade técnica y el compromiso com la democracia y la defensa de los derechos humanos que el los postulantes deben reunir (ARGENTINA, 2003)

Adiante, observamos um parágrafo direcionado exclusivamente para o fortalecimento da participação popular, tida como fundamental para o bom funcionamento do Estado, que como já observamos, é fundamento da teoria constitucional republicana. $\mathrm{O}$ artigo se refere à criação de mecanismos que permitam um diálogo coletivo ou individual entre indivíduos e o Poder Público.

A partir dessas fundamentações, o referido decreto passa então a estabelecer pré-requisitos formais para a indicação de um candidato à vaga na Suprema Corte, determinando, entre outros dispositivos, uma forte tendência à participação popular. Este novo recurso normativo aposta na transparência e na participação como meios de garantir maior eficiência no processo de escolha de um novo ministro à Corte Suprema. Em seu artigo $4^{\circ}$, o Decreto estabelece obrigatoriedades de publicização e divulgação do nome e do currículo profissional de cada um dos possíveis candidatos à uma vaga na Corte. No artigo seguinte, é determinado que deve também ser declarado pelo próprio candidato uma lista com todas as relações comerciais e contratuais estabelecidas por ele estabelecidas e todas as associações civis e comerciais que o mesmo tenha participado nos últimos oito anos. Com isso, compreendemos que a possibilidade de fiscalização popular e participação direta da população aparece como corolário deste mecanismo estatal, já que a completa divulgação e diversos dados pessoais públicos dos candidatos podem contribuir para a diminuição de casos em que haja favorecimento ou qualquer ação ilegal por parte dos poderes públicos.

Em seguida, está presente o artigo que mais chama atenção neste regulamento, e que consideramos ser o mais forte expoente das características das teorias republicanas do Constitucionalismo Latino-Americano. Em seu artigo 6º o Decreto 222/2003 disponibiliza uma ferramenta de participação da sociedade civil em que é possível formular questionamentos e observações a serem oferecidas ao Poder Executivo Nacional, que após a análise dos 
questionamentos recebidos, deverá decidir se leva ou não adiante a indicação previamente divulgada. Dessa forma, é permitido à cidadãos em geral e entidades vinculadas ao âmbito judicial a participação direta no processo de escolha de um novo ministro da Corte Suprema, formulando perguntas e observações que devem ser levadas em conta pela Presidência em sua decisão.

Art. $6^{\circ}$. Los ciudadanos en general, las organizaciones no gubernamentales, los colegios y asociacones profesionales las entidades académicas y de derechos humanos podrán en el plazo de QUINCE (15) días a contar desde la última publicación en el Boletín Oficial, presentear al MINISTERIO DE JUSTICIA, SEGURIDAD E DERECHOS HUMANOS, por escrito, y de modo fundado y documentado, las posturas, observaciones y circunstancias que consideren de interés expresar respecto de los incluidos en el processo de preselección, con declaración jurada respecto de su propria objetividad respecto de los propuestos (ARGENTINA, 2003).

Retomando as ideias de Roberto Gargarella, em sua obra 200 anos de Constitucionalismo em America Latina, o autor inicia problematizando a questão da desigualdade e comentando o papel das instituições nesse contexto. Gargarella afirma que o problema de desigualdade é observado desde o surgimento das nações latinoamericanas e que as teorias constitucionais constantemente se debruçam sobre este aspecto, já que "las ideas no circulan por un carril independiente del de las instituciones que se crean (GARGARELLA, 2011b). Ou seja, é necessário problematizar as instituições que se encontram instaladas em nossas nações já que muitas delas remontam a períodos autoritários e excludentes. É preciso então, transformar as instituições se queremos uma mudança na perspectiva política do constitucionalismo latino-americano:

El punto es: si el discurso democrático contemporâneo - cualquiera sea la particular visión de la democracia sobre la que se apoye - repudia los supuestos fuertemente elitistas dominantes em los orígenes del constitucionalismo; y nuestras instituciones - tal como assumimos - preservam la marca de aquellos supuestos; luego, es dable esperar que modifiquemos tales instituciones, de forma de ajustarlas a nuestras conviciones presentes. (GARGARELLA, 2011b)

Para Gargarella, o desenho institucional hegemônico na América Latina é uma das ferramentas de limitação da participação popular. O modelo representativo, o Senado, eleições indiretas e em especial a forma de organização do Poder Judicial contemplam alguns desses elementos trazidos pelo autor. Esta conjuntura é fruto da herança constitucional que recebemos das formulações anteriores, em especial as constituições autoritárias do período pós-independentista.

Em decorrência desta conjuntura, surgem tendências antiautoritária, que postulam, na citação de Gargarella do chileno Artega Alemparte: necesario constituir la ponderación de los poderes, la igualdad entre la libertad y la autoridade, el régimen representativo, el país unido y gobernado realmente por médio de sus mandatários (GARGARELLA, 2011b). No século passado, essa tendência se demonstrava principalmente através da bandeira do sufrágio universal, e hoje apreendemos esses postulados através, por exemplo do Decreto 222/2003, que busca democratizar as instituições e fortalecer o caráter participativo e popular do Poder Público.

No âmbito do constitucionalismo, Gargarella defende uma constituição rígida, para que suas garantias 
possam sobreviver no tempo, protegidas da eventual arbitrariedade proveniente de determinados governo (GARGARELLA, 2011b). Por outro lado, a constituição rígida não pode limitar o avanço dos direitos democráticos e restringir possíveis transformações advindas de novas lutas sociais por mais direitos. Como solução para este impasse, surge o controle judicial, que permite mudanças literais e interpretativas no texto constitucional, a depender da conjuntura social e política, com vistas a respeitar a autoridade da maioria ao mesmo tempo em que garante princípios individuais.

Para que este modelo possa ter sucesso, é imprescindível que as nossas instituições sofram mudanças com o objetivo de aprimorar a representação política e democratizar os espaços públicos de decisão, para que o controle judicial consiga atender aos anseios de toda a coletividade. Compreendemos que o mecanismo adotado no processo de indicação de novos ministros à Corte Suprema argentina contribui para o processo descrito, de modo a garantir maior eficiência na seleção de um magistrado que será também responsável pelo controle judicial no país. Dessa forma, o controle judicial, vinculado à mecanismos de participação social, terá a legitimada necessária para reinterpretar os dispositivos constitucionais de modo a atender às demandas populares de forma democrática.

Grande parte dessas considerações pode ser observada na prática, quando damos conta do processo de indicação de um substituto de Raul Zaffaroni, na Corte Suprema argentina, caso que analisaremos a seguir.

\section{A indicação do jurista Roberto Manuel Carlés à Corte Suprema de Justiça da Nação Argentina}

Traremos agora como forma prática de compreensão da argumentação colocada o caso recente de indicação do jurista Roberto Manuel Carlés à Corte Suprema da Argentina, fato que gerou grande mobilização social através da população e também dos mecanismos institucionais de participação popular.

No final do ano de 2014, o então ministro da Corte Suprema Eugênio Raul Zaffaroni comunicou seu desligamento do órgão, e em sua fundamentação, cita uma passagem da Constituição argentina que determina a necessidade de um novo processo de nomeação para os ministros que alcancem a idade de 75 anos. Com a vacância deixada por Zaffaroni, a Presidente Cristina Kirchner propôs a indicação do jurista Roberto Manuel Carlés, de apenas 33 anos, ao cargo. A divulgação dessa proposta gerou intensa movimentação no país, e diversas foram as manifestações e questionamentos realizados contra a indicação da presidência em que se questionava principalmente a pouca idade do candidato e consequentemente sua falta de experiência, como pode ser observado nas diversas manchetes eletrônicas que tratam do tema. ${ }^{8}$

\footnotetext{
${ }^{8}$ Muitas foram as notícias veiculadas por jornais impressos e virtuais, das quais selecionamos algumas para amostragem: Cristina Kirchner propuso a Roberto Carlés como reemplazante de Raul Zaffaroni en la Corte Suprema. La Nación; inapropriado candidato para la Corte Suprema. La Nación; Massa juntará firmas para rechazar a Carlés. La Nación. 
Como determina o Decreto 222/2003, é facultado à população civil participar ativamente do processo de escolha de um novo ministro da Corte Suprema, através de formulação de perguntas e questionamentos em relação ao candidato. Compreendemos que este mecanismo incentiva e impulsiona iniciativas como a da Asociación por los Derechos Civiles, que formulou uma impugnação à candidatura de Roberto Carlés, além de 39 perguntas a serem respondidas pelo candidato em audiência pública no Senado argentino. A impugnação pleiteada pela Associação argumenta sobre a pouca experiência de Carlés quando comparado, por exemplo, com juízes de primeira instância. Indaga ainda sobre a ausência de antecedentes profissionais, acadêmicos e técnicos exigidos, assim como ausência de independência judicial.

O mecanismo de participação instituído pelo Decreto 222/2003 garante que toda a sociedade poderá participar deste processo, garantindo assim maior eficiência na escolha do novo ministro. Conforme o site da Associação:

Las 39 preguntas giran en torno a las declaraciones públicas de Carlés, su interpretación de la Constitución en general, sobre aspectos derivados de la interrelación de normas constitucionales y tratados internacionales de derechos humanos, sobre temas constitucionales específicos y sobre el funcionamiento interno de la Corte Suprema (ASOCIACIÓN, 2015).

Essa ferramenta de participação popular impulsionou a organização da sociedade civil para questionar e discutir a indicação de Roberto Carlés à Corte Suprema. Acreditamos que o Decreto 222/2003 contribuiu de forma determinante para a intervenção da Asociación por los Derechos Civiles, e consequentemente, para a articulação de outros atores nessa campanha. Dessa forma, a edição do Decreto 222/2003 e sua efetiva utilização configuram um avanço na democratização do Poder Judiciário e na implementação de um sistema político calcado na democracia direta e na participação da sociedade. De acordo com o documento formulado pela Associação:

Así, consideramos que en relativo a cuestiones de transparencia, publicidad y participación
ciudadana el mecanismo de autolimitación de facultades del Poder Ejecutivo impuesto por
el decreto $222 / 2003$ y las celebraciones de Audiencias Públicas en el Senado constituyen un
gran avance respecto del anterior sistema a través del cual se efectuaban las designaciones de
jueces de la Corte Suprema de Justicia de la Nación (ASOCIACIÓN, 2015)

No decorrer do documento, a Associação questiona as aptidões do candidato, resgata toda sua trajetória profissional e acadêmica, critica o eventual não preenchimento de pré-requisitos formais e materiais, e por fim formula perguntas ao candidato, a serem respondidas em audiência pública. Acreditamos que a edição do Decreto 222/2003 e sua efetiva utilização tenham sido determinantes para a concretização dessa iniciativa por parte da Asociación por los Derechos Civiles. Importante salientar que esta não foi a única atitude pública mobilizada pela sociedade argentina, mas uma das mais relevantes dada a complexidade da impugnação proposta pela Associação e seu reflexo na sociedade. Essa iniciativa dialoga diretamente com o incremento da participação popular nos 
processos institucionais e, consequentemente, com uma maior eficácia das decisões políticos no que tange à democracia, legitimidade e representatividade. Por fim, após Presidente Cristina Kirchner se viu obrigada a recuar na indicação de Roberto Manoel Carlés, substituindo-o por outros dois candidatos: Eugenio Sarrabayrouse y Domingo Sesín.

\section{CONCLUSÃO}

Ainda que seja discutível o grau de interferência nas deliberações parlamentares (TUSHNET, 2013), o papel contra majoritário da jurisdição constitucional impõe uma separação clara entre a agenda do político profissional e o dever funcional - essa agenda oculta - do juiz. O primeiro responde politicamente aos anseios e aos interesses de seus eleitores. Vivencia o jogo das disputas políticas ordinárias, da retórica, da demagogia e, porque não, de um modelo de racionalidade muito peculiar. Por seu turno, o juiz atende, em tese, aos deveres funcionais de correção e de uma racionalidade própria, um pouco mais distante das disputas políticas ordinárias (BARROSO, 2011). Teoricamente, parece ser evidente que esses mundos ocasionalmente se chocam, ainda mais em momento delicado como a indicação dos ministros da suprema corte (GLOPPEN, 2004).

Contudo, a pesquisa sobre a história oral do Supremo Tribunal Federal revelara dados completamente diferentes. Tal qual no adágio popular de que na prática a teoria é outra, os relatos apresentados mostraram um processo não-conflitivo de indicação e sabatina entre o "candidato" indicado e os senadores. Fora o exemplo quase caricatural do embate entre Sepúlveda Pertence e o senador Roberto Campos, em quase todos os outros houve uma clara deferência do Senado ao indicado, a qual se revela em promoção de elogios e análises rasas sobre os problemas do país. Exemplo paradigmático foi o relato oferecido pelo Ministro Nelson Jobim e as perguntas pré-estabelecidas. O Ministro Eros Roberto Grau relatou sobre as visitas de praxe do candidato eleito aos senadores membros da Comissão de Constituição e Justiça (CCJ) do Senado, procedimento que muito se assemelha em características ao lobby. Dados reveladores também foram apresentados pela movimentação política do advogado Márcio Thomaz Bastos para indicar Cezar Peluso, ainda nos idos do governo Fernando Henrique Cardoso e, depois, como Ministro da Justiça. Ainda aqui, nada de participação popular ou consultas democráticas, mas sim movimentação política de uma influente categoria profissional - advogados paulistas -, e depois, articulações políticas palacianas. O povo ou democracia são sujeitos ocultos, quase sempre marginalizados, no processo de indicação e sabatina do candidato no processo brasileiro. É importante ressaltar que em 2013 foi aprovada pelo Senado Federal a Resolução 41/2013, que implementa procedimento similar ao implementado pelo Decreto 222/2003. Alguns dos dispositivos presentes no decreto argentino figuram nesta ainda nova resolução brasileira, porém, como observamos na primeira parte deste trabalho, não foi constatado nenhum incremento no que se refere à participação popular no processo de indicação de ministros ao STF. Embora tenha 
havido a edição de uma norma, ainda não percebemos sua efetiva utilização, como acontece na experiência vizinha.

O caso argentino parece mais democrático, ainda que possa comportar os mesmos pecados estruturais que afetam todos os processos de reforma constitucional na região (GARGARELLA, 2011a). O decreto kirchnerista 222/2003 alterou os mecanismos de indicação e aprovação de um novo ministro para a Suprema Corte argentina. Venceu a surrada fórmula brasileira do notório saber jurídico e reputação ilibada, os quais, ainda hoje, permitem uma sobrevida normativa do antigo parecer obstaculizador das pretensões políticas de Floriano Peixoto. Compreendemos que as teses republicanas acerca das constituições latino-americanas têm por função balizar as transformações democratizantes em nosso continente. Como formulado por Roberto Gargarella os republicanos defenderam, desde o início, a democracia e a legitimidade da maioria, posicionamentos embasam teorias em toda a história do constitucionalismo latino-americano, e resultam em políticas estatais que apontam para uma cada vez maior participação popular, como o Decreto 222/2003. Em contrapartida, o modelo argentino promoveu uma série de critérios mais precisos e compromissos políticos mais nítidos dos candidatos. Porém, sua maior inovação seria a participação da sociedade civil na sabatina e na oposição ao eventual candidato.

A própria crise instaurada pela indicação do jovem jurista Roberto Manuel Carlés mostrou a vitalidade democrática do próprio sistema de escolha. Primeiro, pela renúncia do Ministro Eugênio Raul Zaffaroni sob o argumento de que a Corte Suprema não era uma monarquia medieval para ser ocupada vitaliciamente. O comportamento incomum foi salutar por permitir um certo compromisso dos juristas latino-americanos com a revitalização das instituições. Em segundo lugar, a reação organizada mostrou não só a atual atenção da sociedade civil argentina sobre o tema, mas também a luta por não haver encastelamento de poder. Nada parece ser mais republicano do que a rotatividade de mandatos (LEWANDOWSKI, 2005).

Entretanto, ainda que o decreto 222/2003 tenha permitido um avanço no cenário argentino e, consequentemente, diminuindo o déficit democrático do processo de indicação e nomeação de ministros no Brasil, os atuais reformadores constitucionais ainda permanecem muito aquém das possibilidades de aberturas possíveis. De um modo geral, o hiperpresidencialismo latino-americano (PULIDO, 2015), face visível de uma matriz de poder definida ainda no século XIX entre conservadores e liberais (GARGARELLA 2013), se converte em pior ameaça para a expansão dos direitos econômicos e sociais.

Isso se deve a incompatibilidade da expansão dos direitos sociais e econômicos e a possibilidade de abertura democrática de um lado e, do outro, um núcleo conservador próprio e refratário a toda e qualquer perda de espaço político - institucional. Logo, a tensão teorética acima mencionada entre o legislador e o juiz, ou, sob uma forma mais contemporânea entre a democracia e a constituição, no contexto latino-americano não se encaixa perfeitamente. Aqui, a profunda desigualdade social e o escopo das diversas gerações de reformistas sociais foram para ampliar direitos sociais e econômicos. O objeto visível era a extrema desigualdade entre uma elite e o restante vol.10, n. 01, Rio de Janeiro, 2017.pp. 1-23 
da população (GARGARELLA, 2015). A aposta ingênua de que bastaria tinta e papel para mudar a realidade socioeconômica da região (BARROSO, 2003) pouco contribuiu para a obtenção da estabilidade política. Ao contrário, a tensão permanente por efetivação de direitos e uma elite política sempre refratária foi e, infelizmente, continua sendo a marca indelével do constitucionalismo latino-americano.

\title{
THE PROCESS OF SELECTING JUDGES FOR THE SUPREMO TRIBUNAL FEDERAL AND THE POSSIBILITIES OF DEMOCRATIZATION OF THE JUDICIARY
}

\begin{abstract}
The Supreme Court is the highest deliberative body of the Brazilian courts, leaving this body all discussions involving constitutional provisions. The court is composed of eleven ministers, who face a procedure involving statement of the Executive and approval by the Senate to fill a seat on the Supreme Court. In this article, we aim to understand the political landscape and the social movements that outline this process, through research of the analysis performed at the Getulio Vargas Foundation: "Oral History of the Supreme Court." From the narratives of the ministers appointed to the Supreme, we will observe this process in the light of the capacity of participation and intervention of society in decisions relating to the subject, what we call popular participation. We use the criterion of participation due to the recent events involving the appointment of a lawyer to the Supreme Court of Argentina, this case highlighted the importance of mechanisms (in this case, Decree 222/2003) to ensure greater intervention of society in institutional processes. As a theoretical basis, we use the doctrine of Roberto Gargarella about Latin American Constitutionalism, and their views on the constitutional theories present in our continent. With that, we will seek to rescue the characteristics of the republican constitutional theory as legal basis for the creation and implementation of instruments of popular participation.
\end{abstract}

Keywords: Suprem Court; Constitucionalism; Constitucional Courts; Supreme Court of Justice of Argentine Nation; Popular Participation.

\section{REFERENCIAS}

ARAGÃO, Alexandre. O controle de constitucionalidade pelo Supremo Tribunal Federal à luz da teoria dos poderes neutrais. Revista de direito da Procuradoria do Estado do Rio de Janeiro. Rio de Janeiro: CEJUR PGE/RJ, vol. 57, nº 1, p. 29 - 41, dez/2002.

ARGENTINA. Constitución de la Nación Argentina. Ciudad de Santa Fe. 1853

Decreto 222/2003. 19 de junho de 2003.

BARROS, Roberto. Dictatorship, legality and institutional constraint. In: Constitucionalism and dictatorship: Pinochet, the Junta, and 1980 Constitution. $1^{\text {a }}$ ed. Cambridge: Cambridge University Press, 2004. cap. 1. p. 10 35 .

BARROSO, Luís Roberto. Direito e política. In: Curso de direito constitucional contemporâneo: os conceitos fundamentais e a construção do novo modelo. $3^{\mathrm{a}}$ ed. São Paulo: Saraiva, 2011. cap.6. p. 415 - 443. 
_ O direito constitucional e a efetividade de suas normas. $7^{\mathrm{a}}$ ed. Rio de Janeiro:

Renovar, 2003.369 p.

BINENBOJM, Gustavo. Agências reguladoras independentes e democracia no Brasil. DIREITO. [S.I], vol. 1, n ${ }^{\circ}$, p. $227-245,2015$.

CAMBIOS EN LA CORTE. Cristina Kirchner propuso a Roberto Carlés como reemplazante de Raul Zaffaroni en la Corte Suprema. La Nación. Buenos Aires. 28 jan 2015. Disponível em: http://www.lanacion.com.ar/1763830-cristina-kirchnerpropuso-a-roberto-carles-como-reemplazante-de-raulzaffaroni-en-la-corte-suprema. Último acesso em 10 Out 2015;

EDITORIAL. Inapropriado candidato para la Corte Suprema. La Nación. Buenos Aires. 05 fev 2015. Disponível em: http://www.lanacion.com.ar/1765767-inapropiadocandidato-para-la-corte-suprema. Último acesso em 10 Out 2015;

ELECCIONES 2015. Massa juntará firmas para rechazar a Carlés. La Nación. Buenos Aires. 08 Abr 2015. Disponível em http://www.lanacion.com.ar/1782494-massajuntara-firmas-para-rechazar-a-carles. Último acesso em 10 Out 2015.

ELSTER, Jon. Forces and mechanism in the Constitution - making process. Duke Law Journal. Durham: Duke University School of Law, vol. 45, n² 2, p. $364-396$, nov/1995.

FONTAINHA, F de C.; SATO, L. S. S. (Orgs.) História Oral do Supremo Tribunal Federal [1988-2013] Vol. 1 Rafael Mayer. Edição FGV Direito Rio: Rio de Janeiro, 2015.

FONTAINHA, F de C.; QUEIROZ, R. M. R; SATO, L. S. S. (Orgs.) História Oral do Supremo Tribunal Federal [1988-2013] Vol. 2 - Aldir Passarinho. Edição FGV Direito Rio: Rio de Janeiro, 2015.

FONTAINHA, F de C.; SILVA, A. M. D. da; NUÑEZ, I. S. (Orgs.) História Oral do Supremo Tribunal Federal [1988-2013] Vol. 3 - Sepúlveda Pertence. Edição FGV Direito Rio: Rio de Janeiro, 2015.

FONTAINHA, F de C.; SILVA, A. M. D. da; SATO, L. S. S. (Orgs.) História Oral do Supremo Tribunal Federal [1988-2013] Vol. 4 - Cezar Peluso. Edição FGV Direito Rio: Rio de Janeiro, 2015.

FONTAINHA, F de C.; MATTOS, M. A. V. L. de; SATO, L. S. S. (Orgs.) História Oral do Supremo Tribunal Federal [1988-2013] Vol. 5 - Sydney Sanches. Edição FGV Direito Rio: Rio de Janeiro, 2015.

FONTAINHA, F de C.; SILVA, A. M. D. da; GUIMARÃES, F. C. (Orgs.) História Oral do Supremo Tribunal Federal [1988-2013] Vol. 6 - Célio Borja. Edição FGV Direito Rio: Rio de Janeiro, 2015.

FONTAINHA, F de C.; PAULA, C. J. de.; NUÑEZ, I. S. (Orgs.) História Oral do Supremo Tribunal Federal [1988-2013] Vol. 7 - Carlos Velloso. Edição FGV Direito Rio: Rio de Janeiro, 2015.

FONTAINHA, F de C.; SILVA, A. M. D. da; SANTOS, C.V. N. dos (Orgs.) História

Oral do Supremo Tribunal Federal [1988-2013] Vol. 8 - Néri da Silveira. Edição FGV Direito Rio: Rio de Janeiro, 2015.

FONTAINHA, F de C.; PAULA, C. J. de.; SATO, L. S. S.; GUIMARÃES, F. C. (Orgs.) História Oral do Supremo Tribunal Federal [1988-2013] Vol. 9 - Nelson Jobim. Edição FGV Direito Rio: Rio de Janeiro, 2015. 
FONTAINHA, F de C.; QUEIROZ, R. M. R.; ACCA, T. dos S. (Orgs.) História Oral do Supremo Tribunal Federal [1988-2013] Vol. 10 - Eros Grau. Edição FGV Direito Rio: Rio de Janeiro, 2015.

GARGARELLA, Roberto. El constitucionalismo latino-americano y la "sala de máquinas" de la constitución (1980-2010). Gaceta Constitucional. Lima: Gaceta Juridica, vol.48, nº 1, p. 289 - 305, dez/2011.

El primer derecho constitucional latinoamericano. Mimeo.

.Liberalism: between tyranny and anarchy. In: The Legal Foundations of Inequality: constitutionalism in the Americas, 1770 - 1860. $1^{\text {a }}$ ed. Cambridge: Cambridge University Press, 2010. cap. 3. p. 153 - 214.

Fragmento del borrador del libro "200 años de Constitucionalismo en América Latina”. Caps. 5 e 6, p. 1-

32.2011. Disponível em: http://seminariogargarella.blogspot.com/.Acesso em: 15/11/2015

Fusion Constitucionalism: the liberal - conservative compact in the second half of the nineteenth century. In: Latin American Constitucionalism, 1810 - 2010: the engine room of the constitution. $1^{\mathrm{a}}$ ed. Nova Iorque: Oxford University Press, 2013.

Cap.2.p. $20-43$.

El nuevo constitucionalismo latinoamericano. Algunas reflexiones preliminares. Crítica y Emancipación. Buenos Aires: CLACSO, vol. 2, n³, p. 169 - 188, jan/jul 2015.

GLOPPEN, Siri; GARGARELLA, Roberto; SKAAR, Elin. Democratization and the judiciary: the accountability function of courts in new democracies. $1^{\text {a }}$ ed. Portland:

Frank Cass Publisher, 2004. Introdução. p. 1 - 7.

LACLAU, Ernesto. A saga do populismo. In: A razão populista. 1ª ed. São Paulo: Três Estrelas, 2013. cap.7. p. 253 -284 .

LEWANDOWSKI, Enrique Ricardo. Reflexões em torno do princípio republicano. Revista da Faculdade de Direito, Universidade de São Paulo. [S.I], vol. 100, p. 189 - 200, jan/2005.

MARINI, Ruy Mauro. A dialética do desenvolvimento capitalista no Brasil. In: Subdesenvolvimento e Revolução. $3^{\mathrm{a}}$ ed. Florianópolis: Insular, 2012. cap. 2. p.73 - 162.

MÉDICI, Alejandro. Teoría constitucional y giro decolonial: narrativas y simbolismos de las constituciones. Reflexiones a propósito de experiencia de Bolívia y Ecuador. Revista de estudios críticos: [S.I], vol.1, nº 1, p. 94 $124, \mathrm{dez} / 2010$.

NINO, Carlos Santiago. The constitution of deliberative democracy. $1^{\text {a }}$ ed. New Haven: Yale University Press, $1996.225 \mathrm{p}$.

OLIVEIRA, Maria Angela Jardim de Santa Cruz. Sobre a Recusa de Nomeações para o Supremo Tribunal Federal pelo Senado. Direito Público, Porto Alegre, v. 25, p. 68-78, 2009.

PULIDO, Carlos Libardo Bernal; FREITAS, Graça Maria Borges. Direitos fundamentais, juristocracia constitucional e hiperpresidencialismo na América Latina. Revista Jurídica da Presidência. [S.I], vol.17, $\mathrm{n}^{0}$ 111, p. $15-34$, fev/maio 2015.

SCHWARTZ, Roberto. As ideias fora do lugar. In: Ao vencedor as batatas: forma literária e processo social nos inícios do romance brasileiro. $5^{a}$ ed. São Paulo: Editora 34, 2000. cap. 1.p. 9 - 32.

TAVARES FILHO, Newton. Democratização do processo de nomeação dos ministros do Supremo Tribunal vol.10, no. 01, Rio de Janeiro, 2017.pp. 1-23 
Federal. Brasília: Consultoria Legislativa da Câmara dos Deputados. 2006.

TUSHNET, Mark. Alternative forms of judicial review. Michigan Law Review. Ann Harbor: Michigan Law Review Association, vol. 101, nº 8, p. 2781 - 2802, ago/2003.

Trabalho enviado em 21 de janeiro de 2016.

Aceito em 14 de julho de 2016. 